\title{
The Himalayan Silver Fir and Aeroplane Construction.
}

$\mathrm{A}^{\mathrm{N}}$ $\mathrm{N}$ important communication (Indian Forest Re search Institute Bulletin, No. 69 Economy Series, 1926) has been recently issued from the Research Institute at Dehra Dun, India, dealing with "The Mechanical and Physical Properties of Himalayan Spruce and Silver Fir." The work of the various branches of the Research Institute is laid down on a triennial basis, lines of investigation to be undertaken being entitled "Projects." The present bulletin refers to timber-testing work under Projects Nos. I. and II. on Picea Morinda and Abies Pindrow.

These two species have been but sparsely utilised by the markets up to date owing to costs of extraction and a lack of knowledge as to the properties of the timbers. They exist in large quantities in northern India. Spruce is found in the Himalayan tracts from Afghanistan to Kumaon, from $7000 \mathrm{ft}$. to $11.000 \mathrm{ft}$. elevation, and commonly mixed with fir, deodar, and Pinus excelsa. The silver fir extends from Afghanistan to Nepal, from $7500 \mathrm{ft}$. to $11,000 \mathrm{ft}$., sometimes as pure crops but commonly mixer with spruce, deodar, and Pinus excelsa, and at times associated with broad. leaved species. It is estimated that existing mixed spruce and silver fir forest could supply a sustained annual yield of more than two million cubic feet, the best localities being enumerated. Both species grow to a large size. Himalyan spruce are reported up to $215 \mathrm{ft}$. in height and as much as $23 \mathrm{ft}$. in girth, whilst the Himalayan silver fir has reached a size of $202 \mathrm{ft}$. in height and $26 \mathrm{ft}$. in girth.

The investigations carried out in the timber-testing branch of the Institute were undertaken in order to ascertain the strengths of the two timbers for constructional, aeroplane, and other purposes. Incidentally, the question as to whether the spruce red wood was inferior to spruce white wood was decided. The impression that such is the case is commonly held. The investigations showed, however, that the red wood, which is simply the darker, denser material near the centre of the lower portion of the tree-trunk, is in no way inferior to spruce white wood when taken from healthy living trees. The tests have demonstrated that the timber of silver fir has proved to be stronger than the spruce, which is also the case, in some parts, with the European species of these genera. Apart from its scientific aspects, the bulletin has botl a commercial and Empire value owing to the deductions derivable from the tests.

The two principal causes which have led to com. plaints, both from the match manufacturer and others, and to the restricted use of these two conifers in India, are the prevalence of knots and the lack of durability of these timbers. The comparison has usually been made with some of India's most valuable timbers, such as deodar, teak, Xylia dolabriformis, and so forth. A similar comparison in Europe would be to contrast silver fir and spruce with oak. The tests have shown that the Himalayan spruce and silver fir are at least as durable as and stronger than the corresponding species of Europe and America. The investigations carried out were made on similar lines and are strictly comparable with the results obtained in the Forest Products Laboratories both in Canada and the United States. The Himalayan silver fir has been proved to be stronger than Sitka spruce (Picea sitchensis), the accepted conifer for use in aeroplane construction. It is held that the Himalayan species are not more knotty than the spruces and firs of other parts of the world, with the exception of the Sitka spruce. The tests have shown that the silver fir is less knotty than the spruce in the Himalaya, and a case appears to have been made out for a careful survey of the denser older forests of the former species with the view of the possibility of their being able to furnish aeroplane material.

It is a common British failing to suppose that the foreigner has a better article than can be obtained in the Empire, so this careful piece of research work deserves to be widely known. For the time is assuredly approaching when the silver fir and spruce belt of the western Himalaya will furnish its quota to assist the rapidly dwindling soft-wood supplies of the globe.

\section{The Influence of Impurities on Copper.}

TTHE work that Prof. D. Hanson and his co-workers have been carrying out on the effect of various impurities on copper of the highest degree of purity is extended in two papers read recently before the Institute of Metals. The first of these, in collaboration with Miss G. W. Ford, deals with the influence of bismuth, the solubility of which in solid copper is less than 0.002 per cent. Small amounts of this element adversely affect the rolling properties of copper, particularly during hot-rolling, and the limiting percentage for this process appears to be less than 0.01 per cent. In cold-rolling, the material fractured when more than about 0.05 per cent. of bismuth was present. Even with smaller amounts the effect is bad, especially where the degree of cold-work is great. The effects of this impurity on the electrical conductivity and tensile strength are small.

The second paper, carried out in collaboration with C. B. Marryat, deals with the influence of arsenic, alone and together with oxygen. Copper containing up to 1 per cent. of arsenic alone is very difficult to produce as completely sound castings, but the presence of a little oxygen greatly improves the casting properties. The copper-arsenic alloys are, however, exceedingly ductile and can be worked, both hot and cold, to almost any desired extent. Arsenic alone has but a small hardening effect on pure copper, the
Brinell hardness of which, in the annealed state, is almost constant, nor is the ductility greatly affected. In the case of cold-worked metal the arsenic does definitely increase the hardness. The ratio of the fatigue range to the tensile strength of arsenical copper is relatively high, about 0.9 ; higher, that is, than in copper containing oxygen or iron. The effect of the element on the electrical conductivity is profound, being much greater than that of either of the two latter metals. It reduces the size of the crystals in the castings, but has no appreciable effect on the structure of worked and annealed copper. The solubility of arsenic in solid copper is about $\mathbf{7 \cdot 2 5}$ per cent, a figure which alters little with temperature.

The simultaneous presence of arsenic and oxygen leads to the following effects. The presence of arsenic reduces the deleterious effects of oxygen on the coldworking properties of copper. As the ratio of arsenic to oxygen is raised the cast bars become more ductile, but, unless this ratio is high, the metal is in an overrolled condition and for severe cold-work the arsenic must exceed ten times the content of oxygen, and a much higher ratio than this is still quite satisfactory. The necessary ratio of these two impurities depends on the amount of cold-work to be done; the greater the amount of cold-working, the greater is the amount of arsenic required. Hot rolling of the copper con-

No. 3002, VoL. 119] 